\title{
Seasonal forecast of Kharif flows from Upper Jhelum catchment
}

\author{
Wolfgang Bogacki ${ }^{1}$ and M. Fraz Ismail ${ }^{2}$ \\ ${ }^{1}$ Department of Architectural and Civil Engineering, University of Applied Sciences, Koblenz, 56075, Germany \\ ${ }^{2}$ National Engineering Services (Pvt) Limited, Lahore, 54000, Pakistan \\ Correspondence to: W. Bogacki (bogacki@hs-koblenz.de) \\ Published: 17 October 2016
}

\begin{abstract}
An operational hydrological forecast model was set-up based on the Snowmelt-Runoff Model (SRM) in order to forecast Kharif flows from Upper Jhelum catchment. Zone-wise degree-day factor functions were derived by diagnostic calibration and are applied according to a defined temperature rule when melting starts. While predicting the depletion of snow-covered area by SRM's modified depletion curve approach, scenario runs with temperature and precipitation of past years are carried out which are evaluated statistically to forecast the seasonal flow volume.
\end{abstract}

\section{Introduction}

Irrigated agriculture provides $90 \%$ of Pakistan's food requirements, $22 \%$ of its Gross Domestic Product and provides employment to $60 \%$ of the population of the country (Euroconsult, 2011). Pakistan ranks 5th in rice export and 8th in wheat production in the world (FAO, 2011). Consequently, agriculture's share in water usage is about $97 \%$, which is well above the global average of about $70 \%$ (Akram, 2009). The Indus Basin Irrigation System, comprising a canal command area of more than 14 million ha, is one of the largest contiguous irrigation systems of the world. On average, annual canal water diversion from River Indus and its major tributaries amounts to about $130 \mathrm{~km}^{3} \mathrm{a}^{-1}$.

Flows in the Indus Basin mainly originate from the high mountain ranges of the Western Himalaya - Karakoram Hindu Kush region. Though the flow regime also comprises glacier melt and runoff from rainfall during monsoon season, the predominant contribution comes from the melting of seasonal snow accumulated during the preceding winter and spring (Archer et al., 2010). Depending on the altitude of the catchment, flows originating from snowmelt start to rise in March to April. Average monthly flow volumes reach their peak in May to July.

Expected flows during the forthcoming Kharif cropping season (April-September) are forecasted by end of March. Based on these forecasts, the Indus River System Author- ity (IRSA) decides the provincial shares and the provincial irrigation departments subsequently determine the seasonal water allocation to the different canal command areas. A reliable seasonal forecast of the water resources to be expected from snowmelt is therefore of utmost importance for the agricultural production.

\section{Study area}

One of only two major reservoirs in Pakistan, the Mangla reservoir, is located at the foothills of the Western Himalayas on Jhelum river (Fig. 1). After a dam raising project completed in 2009, the storage capacity is $9.1 \mathrm{~km}^{3}$, equivalent to about $35 \%$ of mean annual flow in Jhelum river which was approx. $26 \mathrm{~km}^{3} \mathrm{a}^{-1}$ during the period 2003-2011. The snowmelt contribution to annual flows is about $50 \%$ on average, with variations between $45-60 \%$ from year to year. While average monthly flow in Jhelum river starts rising already in February reaching its maximum in May (Fig. 2), peak flood events usually occur during monsoon season in July-September.

The catchment of Jhelum River upstream of Mangla dam has an area of about $33500 \mathrm{~km}^{2}$ and a mean hypsometric elevation of nearly $2400 \mathrm{~m}$ a.s.l. The lowest elevation at Mangla is about $300 \mathrm{~m}$ a.s.l. whilst the highest peak has an altitude of $6285 \mathrm{~m}$. Due to its comparatively low altitude, according to the GLIMS glacier database (Paul and Frey, 2010) only 


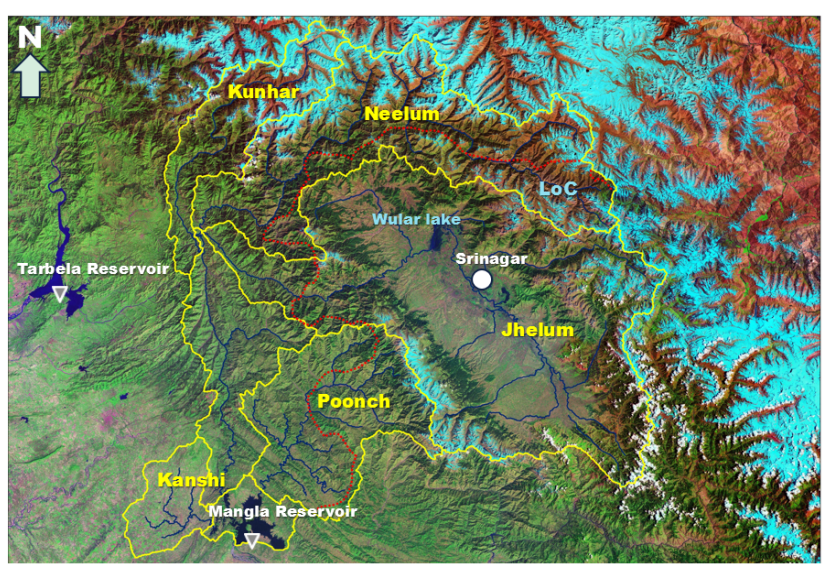

Figure 1. Landsat TM scene of study area.

$0.7 \%$ of the catchment is covered by glaciers or perennial snow thus having no major impact to the flow regime.

\section{Methodology}

\subsection{Snowmelt modelling approach}

Snowmelt is a complex physical process that is primarily driven by the energy flux entering the snowpack. Two categories of snowmelt models exists: energy balance models attempt to quantify the components of the heat balance equation while temperature index models use air temperature as a principal predictor of melt rates. Temperature index models have been widely used as they offer generally a good model performance while data requirements are comparatively low which is of particular importance in remote and rugged mountainous catchments like in the Himalaya Karakoram - Hindu Kush region. Among the class of temperature index models SRM (Martinec, 1975) has become very popular in conjunction with the increasing availability of remote sensing snow cover data, as it circumvents the error prone snow accumulation approach used by other models.

An Excel ${ }^{\circledR}$ version (Bogacki and Hashmi, 2013) of WinSRM (Martinec et al., 2011) was developed in order to allow for changes in the underlying code like the handling of heavy rainfalls that had to be adapted to the catchment characteristics. Furthermore, Excel ${ }^{\circledR}$ is well known to most engineers who can easily adapt the layout or data structure to their specific needs.

\subsection{Data sources}

SRM uses air temperature, snow covered area, and precipitation as daily input variables. The watershed is divided into elevation zones using their mean hypsometric elevation as reference for zone-wise degree-day calculation.

There are three high elevation climate stations in the Pakistani part of the Upper Jhelum catchment operated by

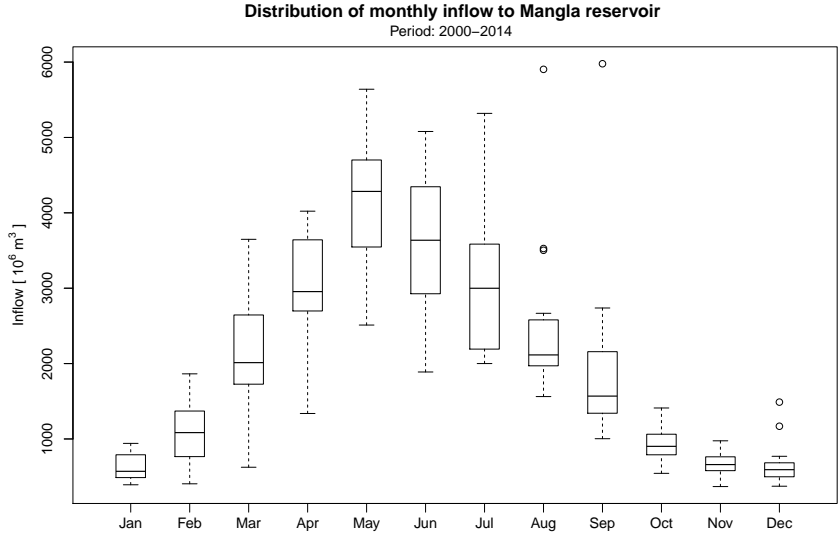

Figure 2. Distribution of monthly inflow to Mangla reservoir 20002014.

WAPDA's ${ }^{1}$ Snow and Ice Hydrology Project, namely Pir Chenasi at 2650, Shogran at 2930 and Saif-ul-Maluk at $3200 \mathrm{~m}$ a.s.l. However none of them has a continuous series of daily data over a longer period and permanent data accessibility that is needed for an operational forecast model. Thus, the WMO climate station at Srinagar airport located at an altitude of $1587 \mathrm{~m}$ a.s.l. was chosen as temperature base station, of which a full set of climatic data can be obtained online from the GSOD ${ }^{2}$ data-base with a time-lag of about 2 days only. Degree-days in each elevation zone are calculated using a constant temperature lapse-rate of $-6^{\circ} \mathrm{C} \mathrm{km}^{-1}$.

The MODIS (Terra) Snow Cover Daily product ${ }^{3}$ with a spatial resolution of approx. $500 \mathrm{~m}$ is used to determine the snow cover of the catchment. As the sensor cannot detect snow below clouds, a cloud elimination algorithm is applied using temporal interpolation between two cloud-free days for each pixel. Afterwards the daily percentage of snow cover area in each elevation zone is calculated and smoothed by moving average.

As spatial interpolation of daily precipitation station data in mountainous regions is particularly difficult, the remote sensing based RFE 2.0 South Asia ${ }^{4}$ daily rainfall product (Xie et al., 2002) is used. According to SRM's elevation band approach, the gridded data having a spatial resolution of approx. $10 \mathrm{~km}$ is mapped to the respective elevation zones.

\footnotetext{
${ }^{1}$ Pakistan Water and Power Development Authority

${ }^{2}$ Global Summary Of the Day. Download at: ftp://ftp.ncdc.noaa. gov/pub/data/gsod/ (NCDC, 2010)

${ }^{3}$ Moderate-resolution imaging spectro-radiometer ftp://n5eil01u.ecs.nsidc.org/SAN/MOST/MOD10A1.005/ (Hall et all., 2006)

${ }^{4}$ RainFall Estimates version 2.0 created by the NOAA Climate Prediction Center's FEWS-NET group (2011-2015) sponsored by USAID. Download at: ftp://ftp.cpc.ncep.noaa.gov/fews/S. Asia/data/
} 

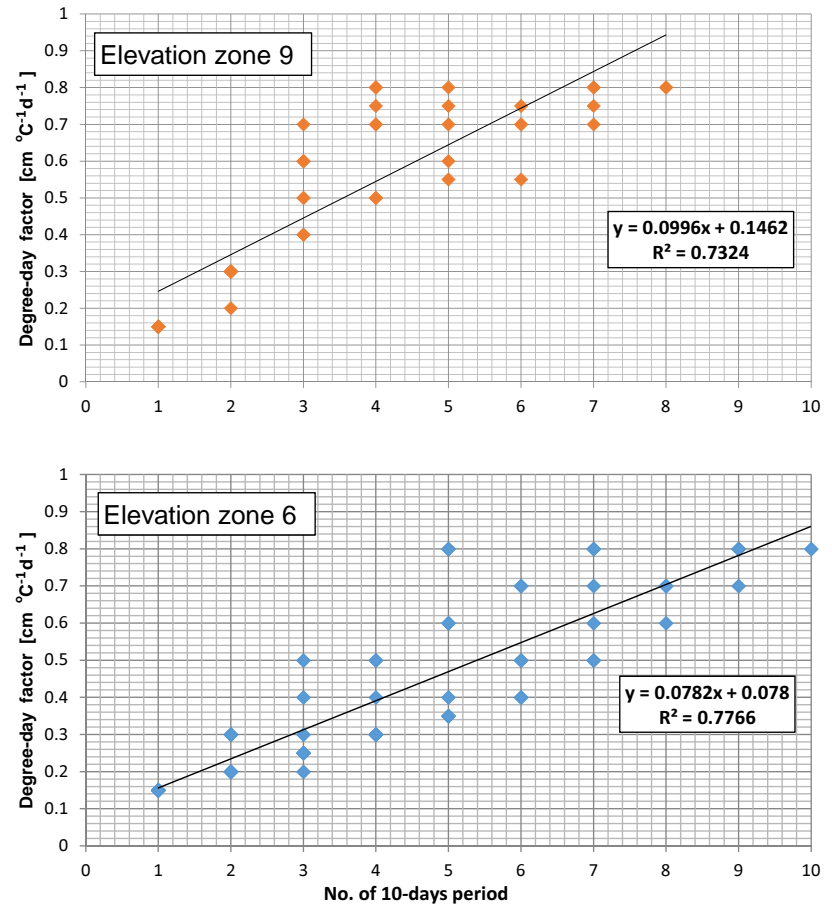

Figure 3. Increase of degree-day factors with time (10-days periods) after melting start for elevation zones 6 and 9. Degree-day factors are obtained by diagnostic calibration.

\subsection{Model parameters}

The most important model parameter controlling daily snowmelt is the degree-day factor $\left[\mathrm{cm}^{\circ} \mathrm{C}^{-1} \mathrm{~d}^{-1}\right]$, which transforms the index variable degree-day $\left[{ }^{\circ} \mathrm{Cd}\right]$ into actual melt $\left[\mathrm{cm} \mathrm{d}^{-1}\right]$. In a first step, best-fitting degree-day factors were obtained in 10-days intervals for each elevation zone by diagnostic calibration matching observed Mangla inflows with the simulated ones.

The degree-day factor generally increases during melt season as the snowpack becomes "ripe" due to accumulation of energy by the time (e.g. Martinec et al., 2011; Hock, 2003). This process happens later at higher elevation zones as temperatures are lower but the increase is quicker than in the lower zones, as energy input by solar radiation is longer in effect until actual melting starts. In order to develop a generalised rule as needed in the forecasting procedure, zone-wise degree-day factor functions (Ismail et al., 2015) where developed. The relation of degree-day factors versus time, i.e. the 10-days periods, was plotted for each elevation zone for all calibrated years, using the first period when the increase commences as starting point. Figure 3 shows the evolution of degree-day factors by time for elevation zones 6 (2500$3000 \mathrm{~m}$ a.s.l.) and 9 (4000-4500 m a.s.l.) respectively. Finally a degree-day factor function was developed by linear regression for each elevation zone of Upper Jhelum catchment (Table 1).
Table 1. Zone-wise degree-day factors depending on 10-days periods after melting start.

\begin{tabular}{lccccccc}
\hline & \multicolumn{7}{c}{ Elevation zone } \\
\cline { 2 - 8 } Period & $1-5$ & 6 & 7 & 8 & 9 & 10 & 11 \\
\hline 1 & 0.25 & 0.31 & 0.27 & 0.32 & 0.35 & 0.34 & 0.34 \\
2 & 0.32 & 0.38 & 0.36 & 0.40 & 0.44 & 0.49 & 0.49 \\
3 & 0.39 & 0.45 & 0.45 & 0.48 & 0.53 & 0.65 & 0.65 \\
4 & 0.46 & 0.52 & 0.54 & 0.56 & 0.62 & 0.80 & 0.80 \\
5 & 0.53 & 0.59 & 0.62 & 0.64 & 0.71 & & \\
6 & 0.59 & 0.66 & 0.71 & 0.72 & 0.80 & & \\
7 & 0.66 & 0.73 & 0.80 & 0.80 & & & \\
8 & 0.73 & 0.80 & & & & & \\
9 & 0.80 & & & & & & \\
\hline
\end{tabular}

The start of melting in each zone differs from year to year, depending on the actual temperature development during spring. Based on average 10-days period temperatures, a forecast rule was developed controlling when to start the respective degree-day factor function in a particular zone. These threshold temperature values decrease from $6^{\circ} \mathrm{C}$ in the lower to $1^{\circ} \mathrm{C}$ in the upper elevation zones.

The other model parameters required by SRM like temperature lapse-rate, recession coefficient, runoff coefficient for snow, lag-time, etc., were applied basin-wide and kept constant for all years. The values of these parameters were determined according to the methods described by Martinec et al. (2011) and slightly adjusted to achieve a good fit over the whole calibration period. Only the procedure of adjusting the recession coefficient for heavy rainfalls, which is hard coded in WinSRM had to be adapted to the catchment characteristics, as otherwise peak runoffs were heavily overestimated.

\subsection{Forecasting approach}

The main objective of the Upper Jhelum snowmelt runoff model is the operational forecast of water availability in the Kharif cropping season (April-September) but the model is also utilised for 10-daily forecasts in order to fine-tune irrigation water distribution during the season. Because mediumterm weather forecasts were deemed more promising than long-term seasonal, in a first analysis 10-daily flow hindcasts were carried out using 15-days temperature and precipitation forecasts from $\mathrm{NCEP}^{5}$ and $\mathrm{ECMWF}^{6}$ weather forecast models obtained from the $\mathrm{TIGGE}^{7}$ archive. However flow

\footnotetext{
${ }^{5}$ National Centers for Environmental Prediction, USA (http: //www.ncep.noaa.gov/)

${ }^{6}$ European Centre for Medium-Range Weather Forecasts (http: //www.ecmwf.int/)

${ }^{7}$ TIGGE (http://tigge.ecmwf.int/), the THORPEX Interactive Grand Global Ensemble, is a key component of the World Weather Research Programme to accelerate the improvements in the accuracy of 1 day to 2 week high-impact weather forecasts.
} 
Table 2. Comparison of annual and Kharif (April-September) mean absolute volumetric error [\%] of 10-daily flow forecasts using (a) scenario approach, (b) NCEP, and (c) ECMWF 15-days weather forecasts.

\begin{tabular}{lrrr|rrr}
\hline & \multicolumn{3}{c|}{ Annual error [\%] } & \multicolumn{3}{c}{ Kharif error [\%] } \\
\cline { 2 - 7 } Year & Scenario & NCEP & ECMWF & Scenario & NCEP & ECMWF \\
\hline 2007 & - & - & - & 6.0 & 12.3 & 11.7 \\
2008 & 10.1 & 9.0 & 26.7 & 7.4 & 8.6 & 22.4 \\
2009 & 10.4 & 11.6 & 22.8 & 6.9 & 10.8 & 23.9 \\
2010 & 13.9 & 21.3 & 32.1 & 9.1 & 17.2 & 27.2 \\
2011 & 7.7 & 8.9 & 12.6 & 6.7 & 7.0 & 13.8 \\
\hline Average & 10.5 & 12.7 & 23.6 & 7.2 & 11.2 & 19.8 \\
\hline
\end{tabular}

predictions based on these weather forecasts were found inferior compared to a scenario approach as described below (Table 2). Thus for the seasonal forecasts only the scenario approach was taken into consideration.

When forecasting the three model variables snow-covered area, temperature, and precipitation have to be predicted. In order to estimate the future depletion of the snow-covered area SRM uses so called "modified depletion curves" which are derived from the conventional depletion curves of each elevation zone by replacing the time scale with the cumulative daily snow-melt depth (Martinec et al., 2011). The decline of the modified depletion curves depends on the initial accumulation of snow and represents the actual snow-water equivalent. When initial snow depth is low the modified depletion curve declines faster than in years when a lot of snow has accumulated.

End of March, when the seasonal forecast is carried out, an elevation zone showing already some decline in snowcovered area, and hence having also some cumulated degreedays, is chosen as "key zone". Comparing the relation of decline in snow-covered area versus cumulated degree-days with a statistical analysis of the modified depletion curves of previous years the actual amount of snow is estimated and the future depletion anticipated accordingly, while assuming similar snow conditions for all elevation zones.

While the snow-covered area and its depletion is calculated only once for the actual season to be forecasted, scenario runs are carried out with historic temperature and precipitation data-sets of various years. This results in an ensemble of predicted seasonal flows representing historic weather conditions from which by statistical analysis a forecast of "most likely" (median) as well as expected flows under "dry" or "wet" conditions can be derived.

\section{Results and discussion}

The final flow forecast model, i.e. using fixed model parameters as well as the developed degree-day factor functions and the start rule as described in Sect. 3.4, was validated for the series of years 2002-2011. The relative volume difference
$D_{\mathrm{v}}$ and the coefficient of determination $R^{2}$ according to the Eqs. (1) and (2):

$$
\begin{aligned}
& D_{\mathrm{v}}=\frac{V-V^{*}}{V} \times 100[\%] \\
& R^{2}=1-\frac{\sum_{i-1}^{n}\left(Q_{i}-Q_{i}^{*}\right)^{2}}{\sum_{i-1}^{n}\left(Q_{i}-\bar{Q}\right)^{2}},
\end{aligned}
$$

These equations are used as model accuracy criteria, where $V$ and $V^{*}$ are the observed and the simulated annual flow volumes, $Q_{i}$ and $Q_{i}^{*}$ are the observed and the simulated daily discharge values, and $\bar{Q}$ is the average observed daily discharge.

The years 2002 and 2011 that had not been used for parameter calibration and determination of the degree-day factor functions resulted in an $R^{2}$ of 0.89 for each year and a $D_{\mathrm{v}}$ of 2.3 and $-2.8 \%$ respectively (NESPAK and AHT, 2012). The total series of years has an average $R^{2}$ of 0.83 and an average absolute volume error of $4.3 \%$. Figure 4 gives an example of simulated versus observed inflow hydrograph.

The forecast capability of the developed model was evaluated by hindcasts for the years 2000-2011 using the same procedures as developed for the operational seasonal forecasts. Meanwhile, real forecasts exist for the Kharif seasons of the years 2012-2015. Results are compared with IRSA's forecasts that are based on a statistical approach and with forecasts from the $\mathrm{UBC}^{8}$ watershed model (Quick and Pipes, 1977) that is used by WAPDA's Snow and Ice Hydrology Project. Figure 5 shows a comparison of the relative error of the forecasted Kharif flow volumes by the different approaches. SRM in conjunction with the scenario approach generally predicts Kharif flows with an error of less than $10 \%$, in many years of less than $5 \%$. The year 2010 was exceptional, as there was an approx. 200 years flood event in the monsoon season.

\footnotetext{
${ }^{8}$ University of British Columbia Watershed Model
} 


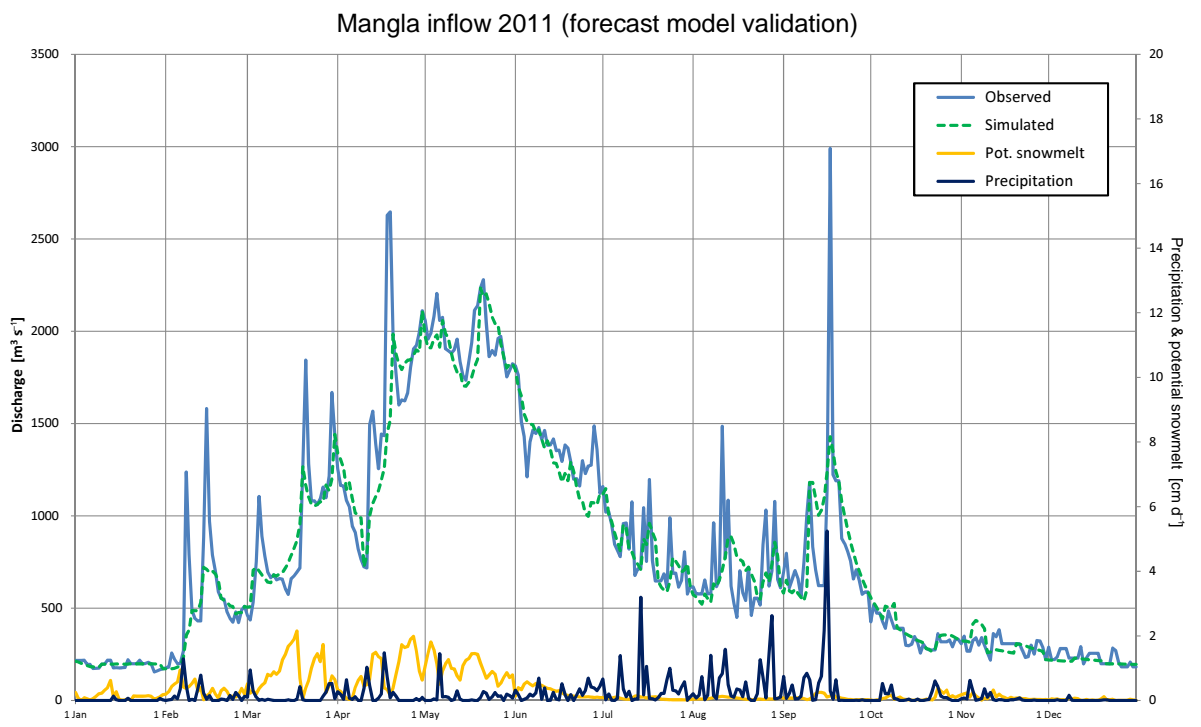

Figure 4. Results of validation of final flow forecast model (dashed line) compared to observed inflows to Mangla reservoir (solid line) for the year 2011. The graph also shows at the bottom rainfall and snowmelt depth [ $\left.\mathrm{cm} \mathrm{d}^{-1}\right]$.

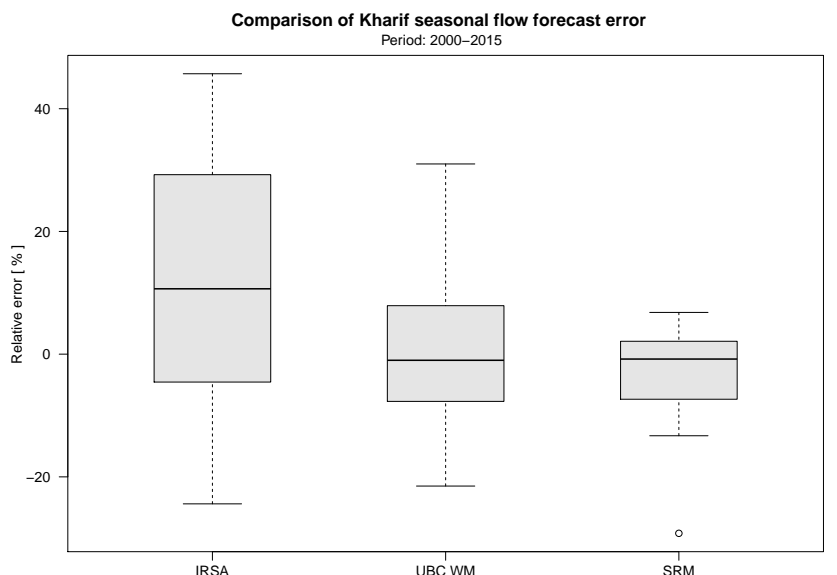

Figure 5. Statistics of relative error of Kharif flow volume forecasts by IRSA's statistical approach, UBC watershed model, and SRM. SRM 2000-2011 are hindcasts, all other forecasts. The series include the approx. 200 years flood in 2010.

The quite good accuracy of seasonal flow prediction in the Upper Jhelum catchment might be due to a combination of favourable factors. One is definitely SRM's good approximation of the actual snow situation at the start of the melting season by utilising the MODIS snow-cover remote-sensing data in conjunction with the modified depletion curve approach. Once the amount of available snow is known, it is most likely, that all snow is melted during the Kharif season.

In addition, the variability of the second important flow component, i.e. rainfall from westerly disturbances in spring and monsoon events in summer, is sufficiently considered by the scenario approach, which transforms the inter-annual variation of precipitation into a series of seasonal flows that can be statistically evaluated. The use of the gridded precipitation product RFE, although it sometimes over- or underestimates a single rainfall event considerably, might also be favourable in that context as the spatial distribution seems to be more fitting as any interpolation of station data in such mountainous regions.

In order to further improve the seasonal forecast capability of the scenario approach, research is under way on the early identification of cold/warm respectively dry/wet years e.g. correlated to the $\mathrm{ENSO}^{9}$ status, which might allow for a more specific selection of a subset of corresponding historic years.

Considering that the error in predicting the Kharif flow volume is less than $10 \%$ in 14 out of 16 years with a mean absolute error in this period of $6.4 \%$ it can be stated that the combination of SRM with remote sensing data and the scenario approach has proven to be a reliable procedure for operational seasonal flow forecasting in the Upper Jhelum catchment. Furthermore this approach could be easily improved if the meteorological characteristics of the forthcoming Kharif season can be teleconnected to global climatic conditions like the ENSO status during the winter.

Acknowledgements. The study was carried out as part of the project "Upgrading of Tools, Water Resources Database, Management Systems and Models" under sub component "B1" of World Bank financed "PK Water Sector Capacity Building \& Advisory Services Project" (WCAP): P110099. The authors thank National Engineering Services Pakistan (Pvt.) Ltd. (NESPAK), Lahore and AHT Group AG, Essen, Germany that they could be part of the

\footnotetext{
${ }^{9}$ El Niño Southern Oscillation
} 
project team. They are highly grateful to civil engineering department of University of Engineering and Technology Lahore and civil engineering department of Hochschule Koblenz, University of Applied Sciences, for supporting subsequent research and wish also to express their high gratitude to Indus River System Authority (IRSA) and WAPDA's Snow and Ice Hydrology Project for sharing their forecast results.

\section{References}

Akram, A. A.: Indus Basin water resources, Tiempo, Issue 70, http: //www.environmentportal.in/files/IndusBasin.pdf (last access: 8 August 2016), 2009.

Archer, D. R., Forsythe, N., Fowler, H. J., and Shah, S. M.: Sustainability of water resources management in the Indus Basin under changing climatic and socio economic conditions, Hydrol. Earth Syst. Sci., 14, 1669-1680, doi:10.5194/hess-14-16692010, 2010.

Bogacki, W. and Hashmi, D.: Impact of Climate Change on the Flow Regime of the Mangla Basin. GWSP Conference "Water in the Anthropocene: Challenges for Science and Governance. Indicators, Thresholds and Uncertainties of the Global Water System", Bonn, Germany, May 2013, doi:10.13140/RG.2.1.1934.6167 (last access: 8 August 2016), 2013.

Euroconsult Pakistan (Pvt.) Ltd.: Handbook on Water Statistics of Pakistan, Water Sector Capacity Building and Advisory Services Project (WCAP), March 2011.

FAO: Pakistan and FAO achievements and success stories, http:// www.fao.org/3/a-at014e.pdf (last access: 8 August 2016), 2011.

Hall, D. K., Salomonson, V. V., and Riggs, G. A.: MODIS/Terra Snow Cover Daily L3 Global 500 m Grid V005 [February 2000September 2015], NSIDC Boulder, Colorado USA, updated daily, ftp://n5eil01u.ecs.nsidc.org/SAN/MOST/MOD10A1.005/, 2006.
Hock, R.: Temperature index melt modelling in mountain areas, J. Hydro., 282, 104-115, 2003.

Ismail, M. F., Rehman, H., Bogacki, W., and Noor, M.: Degree Day Factor Models for Forecasting the Snowmelt Runoff for Naran Watershed, Sci. Int. Lahore, 27, 1961-1969, 2015.

Martinec, J.: Snowmelt-Runoff Model for Stream Flow Forecasts, Nord. Hydrol., 6, 145-154, 1975.

Martinec, J., Rango, A., and Roberts, R.: Snowmelt Runoff Model User's Manual, WinSRM Version 1.14. Agricultural Experiment Station Special Report 100, New Mexico State University, Las Cruces, NM 88003, USA, 2011.

NCDC: Global Surface Summary of the Day - GSOD, Version 7 [January 2000-September 2015], National Climatic Data Center, NESDIS, NOAA, U.S. Department of Commerce, Asheville, North Carolina USA, ftp://ftp.ncdc.noaa.gov/pub/data/gsod/, updated daily, 2010.

NESPAK and AHT: Hydrological Flow Forecast Model for Mangla Catchment, Upgrading of Tools, Water Resources Database, Management Systems and Models Under Sub Component "B1" of WCAP, Final Report, 2012.

NOAA Climate Prediction Center's FEWS-NET group: RainFall Estimates version 2.0, ftp://ftp.cpc.ncep.noaa.gov/fews/S.Asia/ data/, May 2001-September 2015.

Paul, F. (submitter), Frey, H., and Paul, F. (analysts): GLIMS Glacier Database, Boulder, CO, National Snow and Ice Data Center, 2010.

Quick, M. C. and Pipes, A.: UBC watershed model, Hydrol. Sci. Bull., 221, 153-161, 1977.

Xie, P., Yarosh, Y., Love, T., Jonowiak, J. E., and Arkin, P. A.: A real-time daily precipitation analysis over south asia. Preprint of the 16th Conference on Hydrology, Orlando, Florida, American Meteorological Society, Washington DC, USA, 2002. 